OPEN ACCESS

Edited by:

Floria M. K. Uy,

University of Rochester, United States

Reviewed by:

Shailee Shah,

Columbia University, United States

Patrick Kennedy,

University of Bristol, United Kingdom

*Correspondence:

Mark E. Laidre

mark.laidre@dartmouth.edu

Specialty section:

This article was submitted to

Social Evolution,

a section of the journal

Frontiers in Ecology and Evolution

Received: 28 August 2021

Accepted: 25 November 2021

Published: 14 December 2021

Citation:

Laidre ME (2021) The Architecture of Cooperation Among Non-kin: Coalitions to Move Up in Nature's Housing Market.

Front. Ecol. Evol. 9:766342. doi: 10.3389/fevo.2021.766342

\section{The Architecture of Cooperation Among Non-kin: Coalitions to Move Up in Nature's Housing Market}

\author{
Mark E. Laidre* \\ Department of Biological Sciences, Dartmouth College, Hanover, NH, United States
}

The evolution of cooperation among non-kin poses a major theoretical puzzle: why should natural selection favor individuals who help unrelated conspecifics at a cost to themselves? The relevance of architecture to this question has rarely been considered. Here I report cooperation among non-kin in social hermit crabs (Coenobita compressus), where unrelated conspecifics work together to evict larger individuals from a housing market of architecturally remodeled shells. I present (1) the first detailed description of natural coalitions in the wild and (2) a theoretical framework, which examines the evolutionary benefits to each coalition member and predicts when forming a coalition will be successful. In the wild, important ecological and social constraints exist, which are built into the model. Based on these constraints, I show that coalitions can be a successful strategy if several key criteria hold: the coalition is necessary, effective, stable dyadically, and stable polyadically. Notably, the "splitting the spoils" problem-which often undermines non-kin cooperation - is eliminated via architecture: a small individual (C) who helps a medium individual (B) to evict a large individual (A) will ultimately benefit, since C will get B's left behind shell after B moves into A's shell. Coalitions, however, can break down due to added layers of social complexity involving third-party "free riders" and "cheaters," which strategically butt in the architectural queue and thereby steal incentives from the smaller coalition member. Overall, therefore, substantial scope exists for both cooperation and conflict within nature's housing market of architecture. Experiments are now needed to directly test the impact on coalitions of architecture, from the interior of homes up to whole housing markets.

Keywords: architecture, coalitions, cooperation, conflict, cheaters, free riders, housing market, sociality

"But it will be like an old abandoned shell. There is nothing sad about old shells." -The Little Prince, p. 91

\section{INTRODUCTION}

Cooperation poses one of the major theoretical puzzles in evolutionary biology. Why should natural selection favor individuals who help others at a cost to themselves? Fifty years of theoretical and empirical work has demonstrated the importance of shared genetic material in promoting cooperation among kin: kin share genes in common, and these genes can be indirectly passed on through a genetic relative, so helping kin can be evolutionarily favored (Hamilton, 1964a,b). 
An elegant theoretical distillation for kin selection and inclusive fitness is Hamilton's rule $(\mathrm{rB}>\mathrm{C})$, which has been supported by an abundance of empirical studies on cooperation among kin (reviewed in Bourke, 2011). Yet explaining and predicting cooperation among non-kin has remained a central theoretical challenge ever since Darwin (Rubenstein and Abbot, 2017). In contrast to kin, non-kin have no vested genetic interest in helping one another, so why should non-kin ever cooperate?

Analogous to the alignment of genetic interests among kin, there may exist other significant, if more ephemeral, alignments of evolutionary interests among non-kin, which can potentially favor the evolution of cooperation among non-kin (Hammerstein, 2003; Akçay, 2018). Several theoretical solutions have been proposed for non-kin cooperation (MestertonGibbons and Dugatkin, 1992), including reciprocal altruism (Trivers, 1971; Axelrod, 1984), indirect reciprocity (Nowak, 2006; Nowak and Highfield, 2012), group selection (Sober and Wilson, 1999), as well as various types of mutualisms, in which cooperating parties need not act altruistically but can instead mutually benefit simultaneously (Clutton-Brock, 2009). Coalitions represent a form of non-kin cooperation which cuts across many theoretical explanations and which may be mediated by a diverse array of ecological and evolutionary variables (Harcourt and de Waal, 1992; Mesterton-Gibbons et al., 2011). In a coalition, two or more unrelated individuals cooperate, opportunistically working together as a team, often to achieve a cooperative goal that no one individual could attain alone (Sigmund, 1993). Interestingly, the members of a coalition need not have interacted before, and their cooperation can be relatively temporary, arising only because their selfish evolutionary interests momentarily align (Sigmund, 2010). Much theoretical modeling (e.g., Mesterton-Gibbons et al., 2011) has therefore been devoted to understanding how and why the evolutionary interests of coalition members can overlap, including when this synergy may break down, thereby unraveling the cooperation. Notably, even if a temporary alignment of interests enables a coalition to attain its cooperative goal, a major dilemma exists once this goal is successfully realized: splitting the spoils that are the rewards of the joint cooperative effort (Harcourt and de Waal, 1992). This so-called "splitting the spoils" problem often arises because one member of the coalition, particularly the more powerful one, may monopolize the resulting spoils, thereby eliminating any evolutionary incentive for the other, less powerful coalition member to have even cooperated at all. Consequently, a fundamental mystery must be resolved for all coalitions: not just how and why the evolutionary interests of non-kin align to commence cooperation, but also how and why such non-kin cooperation perseveres and is not ultimately undermined by the "splitting the spoils" problem. Insight into potential solutions to this mystery might be had by considering coalitions in the context of architecture.

Architecture permeates the lives of many organisms-from microbes to invertebrates to vertebrates to humans-and it is represented by both the size as well as the internal and external design of an immense variety of constructed and modified homes and dwellings, such as burrows, nests, and other built structures in which animals live (Laidre, 2021a). Such architecture can thus provide an evolutionary setting (Akçay, 2020) in which social behaviors and cooperation may evolve. Yet despite half a century of empirical study of animal architecture (von Frisch, 1974), as well as an equally long historical span of theoretical models of coalitions (Mesterton-Gibbons et al., 2011), these two fields of inquiry have largely existed independently. To my knowledge, no studies-theoretical or empirical-have considered the intersection of architecture and coalitions. Critically, architecture channels and constrains individuals' physical movements (von Frisch, 1974), social decisions (Pinter-Wollman et al., 2017), and overall living parameters (Gould and Gould, 2007; Arndt and Tautz, 2013), with architectural dwellings also often being limited in their availability and especially valuable as resources (Hansell, 2005). Hence, it is plausible that architecture-simply by limiting and constraining individuals' options-might indirectly align the evolutionary interests of unrelated, even competing individuals. Indeed, variable architecture exists precisely because there are often discrete boundaries as to which architectural dwellings are optimal for different individuals (e.g., due to variation in individuals' sizes or other individual-based needs: Bonner, 2006; Arnott and Elwood, 2008; Perna and Theraulaz, 2017). Notably, once different individuals' dwelling requirements vary, the problem afflicting coalitions-that of "splitting the spoils" - might be eased or even entirely eliminated due simply to the fact that each member of a coalition has different architectural preferences for the spoils. Thus, investigating the intersection of architecture and coalitions could yield novel, unexplored insights into theoretical solutions for the evolution of cooperation among non-kin.

As a step toward unearthing deeper connections between architecture and non-kin cooperation, it may be helpful to seek inspiration from an empirical system, one in which architecture is central to individuals' social decisions and ultimately reproductive fitness. With a vast distribution of exchangeable and tradeable homes, the shells of hermit crabs have been referred to as "nature's housing market" (Vermeij, 1993, 2010; Laidre, 2012a; Laidre and Vermeij, 2012). This housing market represents an architectural platform that can generate rich scope not only for conflict, but also potentially for cooperation (Scales, 2015). In particular, highly social terrestrial hermit crabs (Coenobita spp.) are dependent upon conspecifics for architecturally remodeled shells, which have carved out interiors, and these shells can only be acquired after fellow conspecifics die or are evicted (Laidre, 2012b, 2018a, 2021b; Valdes and Laidre, 2019; Doherty and Laidre, 2020). Furthermore, due to a planktonic dispersal stage in the ocean, which separates kin early in their lives before they reach land, these social hermit crabs interact almost exclusively with non-kin (Laidre, 2014). Each individual crab interacts and competes with conspecifics, while attempting to "move up" to larger shells in the housing market, thereby advancing its reproductive success (Laidre, 2010, 2013a,b; Steele and Laidre, 2019). Interestingly, despite their selfish individualistic pursuits, social hermit crabs have frequently been observed cooperating among non-kin by forming temporary coalitions, in which two individuals work together to evict another individual from its shell (e.g., Bates and Laidre, 2018; Laidre, 2018b; Doherty and Laidre, 2020). However, there 
has been no in-depth theoretical consideration of how and why these coalitions emerge; nor has there been any analysis of what prevents these coalitions from being undermined by the "splitting the spoils" problem. By examining the architectural housing market of these coalitions, including the social processes by which architectural vacancies higher in the housing market flow down to others below (Laidre, 2019a), it may help shed light on how and why cooperation among non-kin arises in such a fiercely competitive housing market.

Here I leverage over a decade of naturalistic observations of coalitions among the social hermit crab species Coenobita compressus to build a theoretical framework, which seeks to elucidate how and why coalitions are favored within the architectural context of housing markets. Like the theoretical framework originally developed to understand baboon coalitions (Noë, 1990, 1994), which has since been generalized more broadly (Noë et al., 2001), the theoretical framework developed here on coalitions among social hermit crabs might ultimately be extended to other systems with architecture, spurring greater empirical study and experimental tests. I begin by detailing the behaviors and players that underpin coalitions among social hermit crabs, including: the two members comprising the coalition; the target that the coalition seeks to evict; each party's decision options; and the relevance of outside third parties from the broader collective of "fission-fusion" social groupings (Couzin and Laidre, 2009). Next, I leverage these empirical details as a foundation for the theoretical framework, which distils down relevant ecological, evolutionary, and social variables, all of which interact to dictate the benefits and costs accruing to each party. This theoretical framework not only seeks to illuminate why coalitions exist in social hermit crabs, it also seeks to reveal more broadly why architecture and housing markets can foster coalitions. Critically, the theoretical framework generates unique, testable predictions about which specific dyads will versus will not form coalitions, which coalitions will be stable, and when dyadically stable coalitions may nevertheless break down due to polyadic social complexity involving third-party cheaters and free riders. Ultimately, all the predictions from this theoretical framework can be subject to future tests (see Discussion), including experimental tests within social hermit crabs, as well as within other systems where coalitions intersect with architecture.

\section{EMPIRICAL FOUNDATION: NATURAL COALITIONS IN THE WILD}

Coalitions among social hermit crabs (Coenobita compressus) have been observed for over a decade by the author, his collaborators, and his students, having been referred to in prior studies of many other aspects of this study system (see Laidre and co-author references spanning 2010 to 2021 in our study population in Osa Peninsula, Costa Rica). Yet systematic data has not been collected on these coalitions, and aside from relatively brief mentions-e.g., "Intriguingly, unrelated individuals can also team up in opportunistic coalitions, jointly evicting third parties from their shells" (Laidre, 2018b, p. 239)_no more detailed descriptive accounts exist in the literature. Here I therefore give

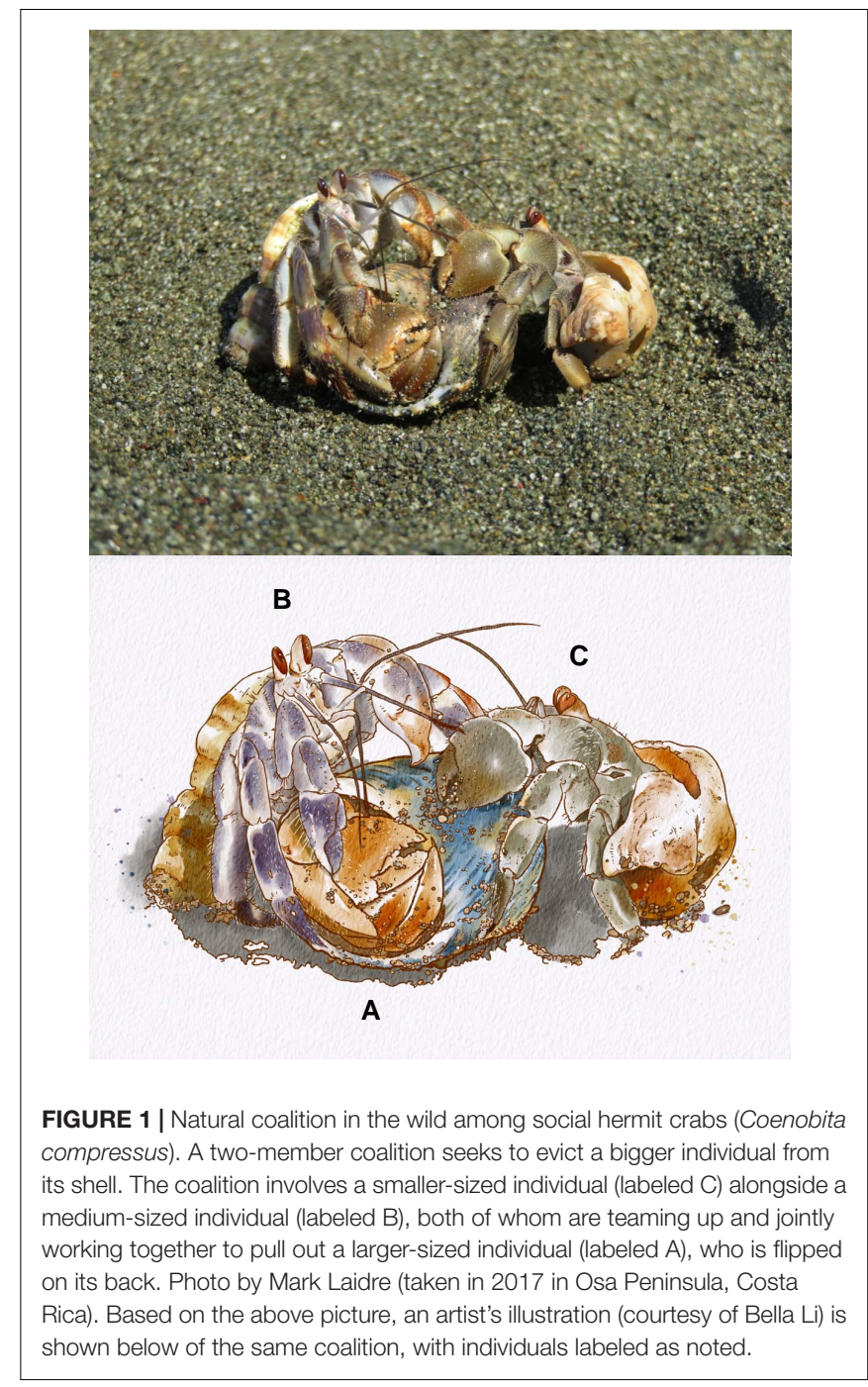

a more in-depth description of these natural coalitions in the wild, including the first published photographs (Figures 1, 2). These descriptions provide an empirical foundation for the subsequent main focus of the paper, namely the theoretical framework that follows.

Coalitions typically involve two individuals (a pair), with a third individual being the target that the two-member coalition seeks to evict from its shell (Figure 1). Both members of the coalition have shells of their own, but these individuals and their shells are virtually always smaller than that of the target individual and its shell. Sometimes, based on the commotion and struggle generated during an attempted eviction, additional individualsbeyond the target and the core two-member coalition-are attracted to the area. These additional individuals-referred to as "third parties" or "bystanders" - are not part of the actual coalition, since they do not help at all to evict the target. Generally, third parties simply wait in the vicinity and sometimes position themselves in a social chain, which emanates from the back of the shell of one or both of the coalition members (Figure 2). This positioning in a social chain enables third parties 

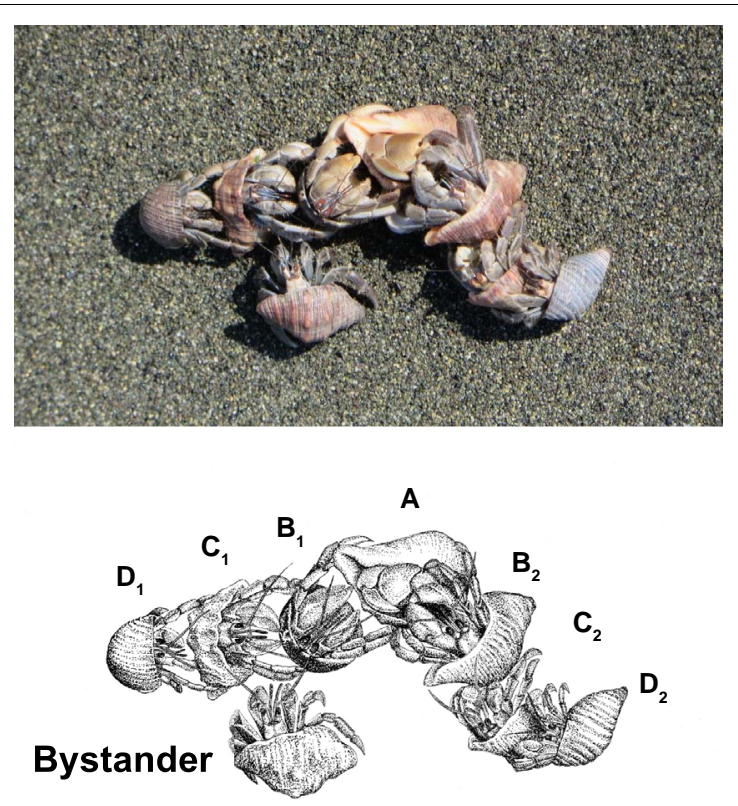

FIGURE 2 | More socially complex, natural coalition in the wild among social hermit crabs (Coenobita compressus). The polyadic arrangement involves a core coalition of two individuals (labeled $B_{1}$ and $B_{2}$ ) who seek to evict a bigger individual (labeled $A)$. The triad $\left(A, B_{1}\right.$, and $\left.B_{2}\right)$ is surrounded by third parties (labeled $C_{1}, C_{2}, D_{1}, D_{2}$, and Bystander). $B_{1}$ and $B_{2}$ each exist at the head a social chain (one chain being $B_{1}, C_{1}$, and $D_{1}$, and the other chain being $B_{2}$, $\mathrm{C}_{2}$, and $\mathrm{D}_{2}$ ). Notably, these additional individuals emanating from behind $\mathrm{B}_{1}$ and $B_{2}$ provide no help to the core two-member coalition. Rather, these additional individuals are merely "free riders" that may indirectly profit if the coalition succeeds at evicting the target. In some cases, third-party "free riders" may act as "cheaters," stealing the incentives from one of the coalition members by strategically butting in the queue without providing any help. An individual labeled "bystander" simply waits in the vicinity, but is not part of either of the social chains. Photo by Mark Laidre (taken in 2014 in Osa Peninsula, Costa Rica). Based on the above picture, an artist's illustration [from Laidre (2018b)] is shown below of the same coalition, with individuals labeled as noted.

to indirectly benefit, since in the event an eviction succeeds, it can catalyze a succession of back-to-back shell swaps (see Laidre, 2019a). Third parties are thus, in effect, "free riders" (Sigmund, 2010), since their positioning around the coalition offers no advantage whatsoever to the coalition itself as it works to evict the target. Indeed, whether third parties are positioned in a chain or not, they merely wait, performing no pulling actions and never adding any strength or providing any help to the two-member coalition. Interestingly, based on precisely where third parties position themselves, some may potentially even undermine the coalition (see below), effectively acting not merely as "free riders" but as "cheaters" (Sigmund, 2010). Finally, if too many bystanders accumulate, it can lead to chaotic jockeying and repositioning, with the original coalition separating.

Whether with third parties present or not, the two members of the coalition attempt to physically evict the target. The target remains flipped on its back (i.e., with the dorsal side of its shell on the ground) and the opening of the target's shell faces upward, allowing both coalition members to use their claws and legs to grab at and pull the anterior portion of the target's body. As the coalition forcibly pulls, the target attempts to resist by clinging inside its shell. Typically, the two coalition members both pull simultaneously; though at times the two may alternate attempts at pulling, each doing so sequentially as one or the other member briefly rests. Both members of a coalition appear strongly involved, in terms of time and effort. Yet coalitions are not always successful. In some cases, one or both coalition members may give up; or the target individual may manage to flip itself over, escape from being pinned down, and run away. If a coalition is successful at evicting the target, the time till eviction occurs can vary widely, from just minutes up to hours (Laidre, personal observation). Once a coalition is successful and the target individual is evicted from its shell, then the evictee is pushed to the side and remains naked and shell-less as one of the coalition members moves into its now empty shell.

To date, the author has observed no evidence for "advance planning" (Shettleworth, 2010) or "complex coordinated signaling" (Laidre and Johnstone, 2013) between the two members of a social hermit crab coalition. In particular, the two coalition members do not travel side-by-side and they do not simultaneously choose who to target for eviction. Instead, these coalitions appear to originate through a simple series of step-by-step individual decisions, in which two, otherwise independent and unrelated individuals opportunistically converge on an acceptable target. Indeed, in all the hundreds of instances of natural coalitions that the author has observed in the wild, an initial lone individual first flips and pins down a target individual, an act which appears to require minimal effort compared to actually pulling the target out of its shell; only later, as the initial lone individual is holding the target individual down and pulling at its body, does another lone individual approach the eviction site and assess the situation. This second individual then can either move on; can choose to do nothing and remain a bystander; or else can join the initial individual in the attempted eviction, thereby forming a coalition. Further experiments on these coalitions (see Discussion) may reveal additional complexity; but presently, simple cues and decision rules (Shettleworth, 2010) appear to underlie the behavioral dynamics of these coalitions. Below I therefore keep the theoretical framework as simple as possible.

\section{THEORETICAL FRAMEWORK: A CONCEPTUAL MODEL FOR THE ARCHITECTURE OF COALITIONS}

To begin, I outline a series of basic assumptions, which lay the foundation of the theoretical framework. Each assumption derives from established knowledge about relevant ecological, evolutionary, and social constraints in the system, as well as key aspects of the above natural history description from wild coalitions. The theoretical framework thus remains faithful to important, real world details of the study system, while at the same time potentially being generalizable to other systems. Next, I delineate several possible evolutionary strategies, which 


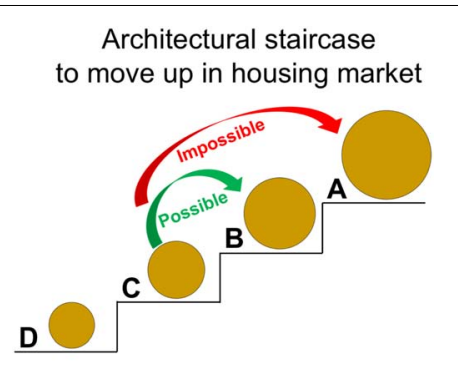

Individuals on same C stair

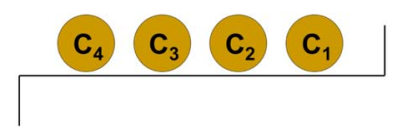

FIGURE 3 | Conceptual model for the architecture of coalitions. In this simple theoretical framework, individuals must climb an architectural staircase to move up in the housing market of shells. The size of each circle in the diagram represents the relative size of individuals and their shells. Letters denote individuals on each separate stair of the staircase, which occupy a given size of shell (i.e., $\mathrm{D}<\mathrm{C}<\mathrm{B}<\mathrm{A}$ represents individuals on four separate stairs, each of whom occupy shells of increasing size). Letters with subscripts denote individuals on the same stair (i.e., $\mathrm{C}_{4}, \mathrm{C}_{3}, \mathrm{C}_{2}, \mathrm{C}_{1}$ represents four distinct individuals on stair $\mathrm{C}$, each of whom occupy shells of equivalent size). For a focal individual on stair $C$, the green arrow displays a possible move of one step up, while the red arrow displays an impossible move that skips steps (see main text for assumptions of the model). In all subsequent figures, a similar schematic is used to show the model's key predictions about criteria that must hold for a coalition to form and be successful as an evolutionary strategy.

individuals could use to advance in the housing market, including a coalition strategy. Based on the assumptions and available strategies, the theoretical framework then predicts criteria that are critical for coalitions to form and be a successful strategy.

\section{Assumptions}

Consider a staircase of architecture (Figure 3), each stair of which represents individuals occupying a given size of shell. For every "step up" to a higher stair, individuals on that higher stair occupy a larger shell size than those on the stair below. Letters are used to denote individuals on each separate stair of the staircase (i.e., $\mathrm{D}<\mathrm{C}<\mathrm{B}<\mathrm{A}$ represents individuals on four separate stairs, each of whom occupy shells of increasing size). Letters with subscripts are used to denote individuals on the same stair (i.e., $\mathrm{C}_{4}, \mathrm{C}_{3}, \mathrm{C}_{2}, \mathrm{C}_{1}$ represents four distinct individuals on stair $\mathrm{C}$, each of whom occupy shells of equivalent size). Four key assumptions are made as individuals navigate this staircase:

(i) All individuals seek to "move up" the staircase, for it is only by rising to larger shells within the housing market that individuals can increase their reproductive success (Laidre, 2010, 2011, 2013a,b, 2019a,b,c; Steele and Laidre, 2019). Larger shells are vital to reproductive success for both sexes, since they enable females to carry more eggs within their shells and enable males to grow bigger, which is essential to gaining access to mates. In our study population, shells span an order of magnitude, from $5 \mathrm{~mm}$ in shell diameter (inhabited by the very smallest individuals) to over $50 \mathrm{~mm}$ in shell diameter (Laidre, 2012a).

(ii) Problematically, every available shell is occupied across all stairs of the staircase (Laidre, 2010, 2012b; Doherty and Laidre, 2020).

(iii) Furthermore, individuals on stairs above are more powerful than those on stairs below, because a tight correlation exists between larger shells being occupied by bigger bodied individuals (Abrams, 1978; Laidre, 2014; Valdes and Laidre, 2018, 2019). Individual condition may occasionally fluctuate (Roberts and Laidre, 2019), but other than molting (when individuals become highly vulnerable) such fluctuations may be slight. Therefore, bigger individuals (who occupy stairs above) are stronger than smaller individuals (who occupy stairs below).

(iv) Finally, individuals can only advance one stair at a time: they cannot "skip steps" when moving up the staircase. For example, an individual on stair $\mathrm{C}$ cannot leap directly up to stair A, without first moving to stair B (Figure 3). This architectural constraint exists because too large a shell-relative to an individual's current body size-is suboptimal (Laidre and Trinh, 2014). Indeed, for a small bodied individual to carry the weight of too large a shell, is energetically costly and inhibits its growth (Osorno et al., 2005). Furthermore, a small bodied individual is incapable of completely filling and therefore holding onto too large a shell, making it easily evictable and powerless to defend that shell (Laidre, 2021c). Hence, individuals prefer shells of the appropriate, next size up relative to their current body size. Individuals thus must advance in a step-wise manner, which requires discrete moves to each subsequent stair in the staircase.

\section{Possible Evolutionary Strategies}

The above assumptions imply that the only way for individuals on lower stairs to move up is when individuals on higher stairs above them vacate their shells, which only occurs if those individual either die or are evicted. Three evolutionary strategies are therefore available for individuals on lower stairs:

- "Wait": wait till those above you either die or are evicted by individuals other than yourself.

- "Alone": alone try to evict another individual above you.

- "Coalition": in a coalition with a conspecific, jointly try to evict another individual above you.

Individuals may pursue a mixed strategy, involving all three of the above strategies. Yet the basic division into these three strategies is justified, given that individuals can be observed performing each one in nature (Laidre, 2014). Indeed, the "Alone" strategy cannot simply be interpreted as a precursor or gamble on cooperation: single individuals attempt evictions in isolated areas, with a low-level of conspecific traffic and with visual barriers, which appear to preclude another conspecific 
from joining them in a coalition. Furthermore, in some instances where an individual is attempting an eviction all by itself, but then is later joined by a conspecific, it will kick this attempted joiner back, reinforcing that "Alone" is indeed its own distinct strategy.

Importantly, the first two strategies ("Wait" and "Alone") may not be successful in the absence of the third strategy ("Coalition"). With respect to the "Wait" strategy, death via predation is rare in this system, since architecturally remodeled shells remain outside the bite force of most predators on land (Laidre et al., 2012). Instances of conspecific death therefore occur almost exclusively due to conspecific-induced evictions (Valdes and Laidre, 2019). Moreover, aside from such eviction events, the time individuals would need to wait till others above them died naturally would mean those who waited would never have a chance to grow big enough to reproduce (Laidre, 2018a). Similarly, with respect to the "Alone" strategy, an individual on a lower stair may not, by itself, be able to easily overcome an individual on a higher stair: evicting such a larger individual from its larger shell may be challenging for a smaller individual (although cases may arise where it becomes possible due to the larger individual's condition being severely compromised, e.g., Osorno et al., 1998, particularly if the larger individual is vulnerable due to molting). Thus, if individuals on lower stairs cannot simply wait and often cannot go at it alone, then the "Coalition" strategy represents a vital means of moving up. Below I ask when coalitions will form and be successful. For illustrative purposes, I focus on a coalition involving $\mathrm{B}$ and $\mathrm{C}$, which work together to evict a target $\mathrm{A}$ (see Figure 1).

\section{Predictions}

For a coalition to form and be successful as an evolutionary strategy, the theoretical framework makes a series of predictions about key criteria that must hold. These predictions follow logically from the assumptions and available alternative strategies laid about above. In particular, for a coalition to form and be successful it must be necessary, effective, stable dyadically, and stable polyadically. Below I elaborate on each of these criteria.

\section{Necessary}

Coalitions must be necessary (Figure 4), otherwise individuals would by default be better off pursing either the "Wait" or "Alone" strategies. As noted above, the "Wait" strategy will be futile when natural death of individuals on stairs above is rare. Likewise, the "Alone" strategy will be unsuccessful whenever B is unable to evict A by itself. Hence, an individual B should only pursue the "Coalition" strategy (i.e., initiate an eviction attempt where fellow conspecifics can easily join in) if it is necessary, meaning that, without help, B would not be powerful enough to overcome A's resistance:

$$
\text { Power (B) }<\text { Resistance (A). }
$$

Multiple variables, in addition to raw body size, may potentially contribute to the realized levels of power and resistance. Yet if the above is true, then it follows, given the correlation between shell size and body size in assumption (iii), that an individual on an even lower stair (C) should be even less capable of evicting A by itself:

$$
\text { Power (C) }<<\text { Resistance (A). }
$$

\section{Effective}

If a coalition is necessary, then it must also be effective (Figure 5) at overcoming the target for it to be successful. Critically, a coalition can only be effective when the combined power of both coalition members is sufficient to exceed the target's resistance and thereby pull the target out of its shell. The strength of different coalition members might combine additively or in more complex non-linear ways. Regardless, a smaller coalition member (C) must be strong enough to contribute sufficient additional power, such that the combined power of the coalition (B and $\mathrm{C}$ ) is effective at exceeding A's resistance:

$$
\text { Power }(\mathrm{B}+\mathrm{C})>\text { Resistance }(\mathrm{A}) \text {. }
$$

In contrast, other coalitions (e.g., B and D), in which the smaller of the two coalition members (D) is too weak, may prove ineffective:

$$
\text { Power }(\mathrm{B}+\mathrm{D})<\text { Resistance }(\mathrm{A}) \text {. }
$$

\section{Stable Dyadically}

\section{Coalition Members Should Have Aligned, Not Competing} Evolutionary Interests

Even if a coalition is necessary and effective, its success might be undermined if it is destabilized dyadically, due to

\section{Coalition necessary: alone $B$ cannot evict $A$}

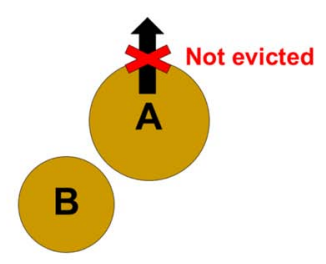
Coalition not necessary:
alone $\mathrm{B}$ can evict $\mathrm{A}$

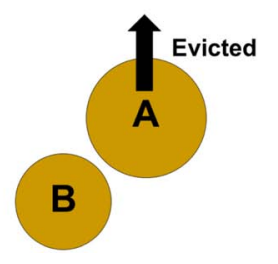

FIGURE 4 | For a coalition to form and be successful, it must be necessary. In this case, alone B cannot evict $A$. 


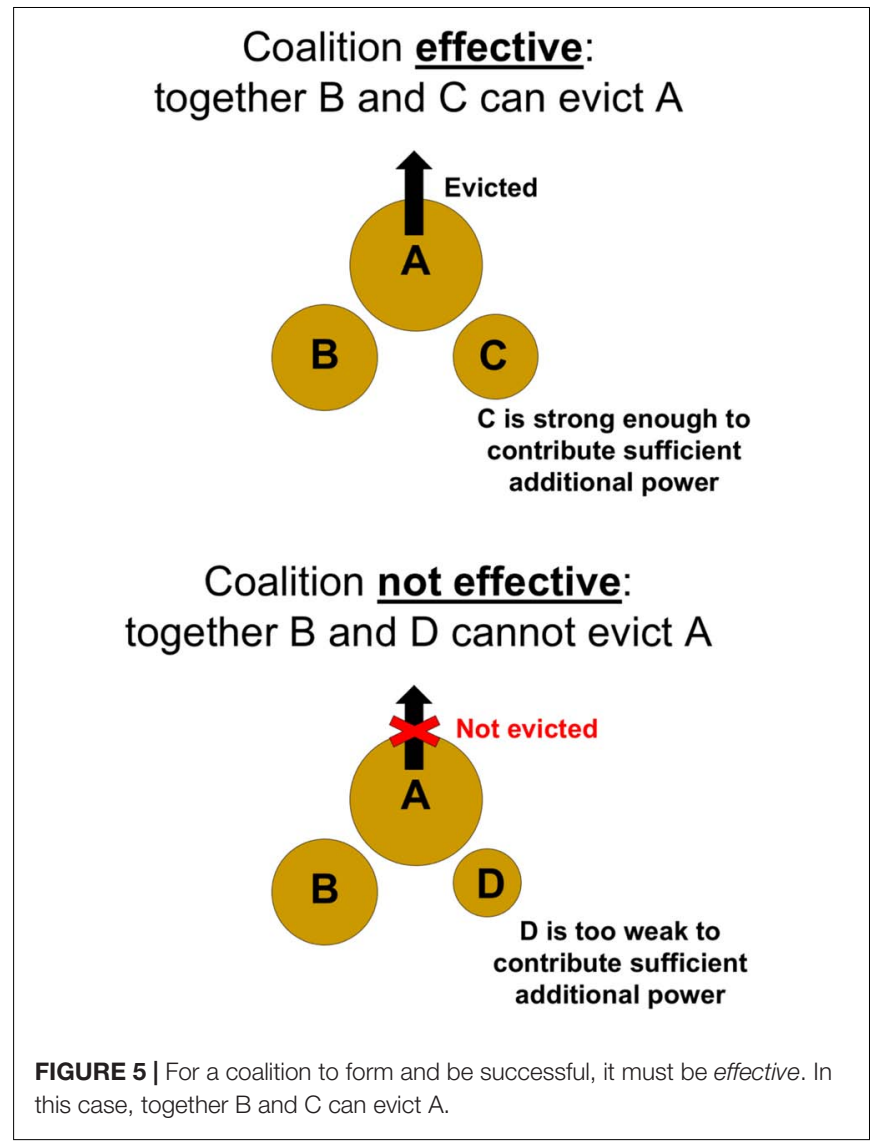

competing interests between the two members of the coalition. It is therefore important that a coalition be stable dyadically (Figure 6) by avoiding conflict and retaining an alignment of interests, from the time the coalition first starts working together to evict the target up to even after the eviction has been realized. Given that post-eviction only one member of the coalition can acquire the shell of the evictee, how do both members of the coalition benefit evolutionarily? In other words, what resolves the "splitting the spoils" problem for this single emptied shell?

Notably, as a corollary of the architectural constraint in assumption (iv), it follows that variable architectural preferences exist for members of a coalition that occupy different stairs. For example, an individual on stair B will seek stair A as its optimal next step, while an individual on stair $\mathrm{C}$ will seek stair $\mathrm{B}$ as its optimal next step. As a consequence of these divergent preferences, an optimal outcome can arise naturally in which both members of the coalition benefit (Figure 6): once the target $A$ is evicted, then B can realize its preferred move into A's empty shell, and after that $C$ can realize its preferred move into B's left behind shell. In effect, C helps B move into A's shell. And such helping is in C's selfish interest, because subsequently $\mathrm{C}$ receives B's passed down shell. Architectural constraints, with their associated variation in individuals' architectural preferences and resource values, can thus eliminate the "splitting the spoils" problem.

\section{Coalition stable dyadically:} aligned evolutionary interests

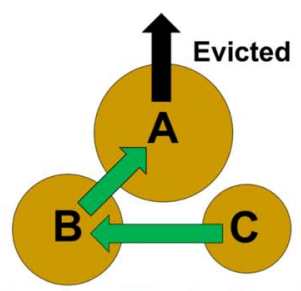

Different architectural preferences: 'splitting the spoils' is not a problem

\section{Coalition not stable dyadically: competing evolutionary interests}

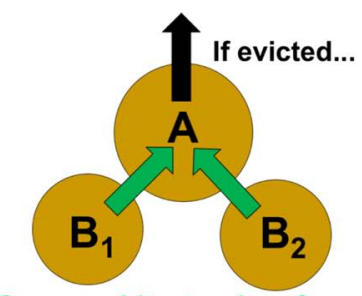

Same architectural preferences: 'splitting the spoils' is a problem

FIGURE 6 | For a coalition to form and be successful, it must be stable dyadically. In this case, B and C have aligned evolutionary interests. This alignment exists due to their different architectural preferences. Thus, after $A$ is evicted, B moves into A's shell and C moves into B's left behind shell, thereby resolving the "splitting the spoils" problem. In contrast, a coalition will not be stable dyadically if individuals have the same architectural preferences, since then the coalition members will have competing evolutionary interests: if $A$ were to be evicted, both $B_{1}$ and $B_{2}$ would compete over moving into A's shell, thereby generating a "splitting the spoils" problem.

In contrast, some potential coalitions, despite being both necessary and effective, may be unstable dyadically (Figure 6). For example, two individuals that both occupy stair $B\left(B_{1}\right.$ and $B_{2}$ ) could have a combined power that is more than sufficient to overcome an eviction target (A). However, if both individuals were to work together to evict $A$, then once $A$ is actually evicted, $\mathrm{B}_{1}$ and $\mathrm{B}_{2}$ will come into direct conflict: their previously aligned interests will collapse and they will become competitors for A's empty shell. Such a free-for-all would not just entail a 50-50 chance of the spoils, but rather could lead to quite dangerous and costly outcomes for one or both parties. In particular, if two individuals lack dyadic stability, and hence are willing to squabble over an evictee's shell after it is evicted, then there is a non-negligible chance that one or both may ultimately lose their original shells. As these two former coalition partners simultaneously attempt to enter the larger empty shell of the evictee, struggling with one another to be first, then the evictee, as well as other individuals passing by, could easily move into their original shells, potentially leaving them with an even less suitable shell due to their own conflict over the spoils. Perfect harmony 
and alignment of interests may not always be possible between coalition members. Yet an inherent dyadic instability will exist for those coalitions in which neither member stands to benefit from the shell left behind by the other member (and hence where both members' architectural preference is for the shell of the evictee). Such dyadically unstable coalitions should therefore be less likely to persevere and may also form less frequently than coalitions that are dyadically stable.

\section{Stable Polyadically}

Incentives for Smaller Coalition Member Must Not Be Stolen by Third Party "Cheater"

Even if necessary, effective, and stable dyadically, a coalition poised for success might be destabilized polyadically (Figure 7) due to the arrival of third parties. One way such polyadic instability could be introduced is if, in addition to the eviction target (A) and the two core coalition members (B and C), a third party arrives that is on the same stair as the smaller of the two coalition members $(\mathrm{C})$. To differentiate these individuals occupying the same stair, we designate the original coalition member as $\mathrm{C}_{1}$ and the third party as $\mathrm{C}_{2}$. Importantly, depending on where $C_{2}$ positions itself, it has the potential to eliminate any incentive for $\mathrm{C}_{1}$ to continue helping as part of the original coalition. This is because for the coalition to function, the two coalition members ( $B$ and $C_{1}$ ) must each reach into the target A's shell as they pull, which requires their bodies be oriented inward, while their shells are directed outward, typically on opposite sides of the target (see Figure 1). Consequently, $C_{2}$ can effectively "butt" in the queue by physical positioning itself immediately behind and clinging to the shell of $\mathrm{B}$ (Figure 7), thereby being in a strategically superior position-compared to $\mathrm{C}_{1}$ - to move into B's left behind shell, should an eviction succeed. Operationally, $\mathrm{C}_{2}$ can thus act as a "cheater": without helping at all, and yet by taking the prime position, it can stand to steal all the rewards of $\mathrm{C}_{1}$ 's cooperative effort. The more third parties that arrive on this same stair (e.g., $C_{2}, C_{3}, C_{4}$, etc.), the greater the chance that one or more might cheat in this way, thereby taking away the evolutionary incentives for the smaller coalition member to help, and ultimately leading to a breakdown of the original coalition.

This third-party cheater problem can be averted if the third party that arrives is on a stair below C (i.e., D). In that case, individual D cannot act as a "cheater" but merely as a "free rider" (Figure 7). This is because D naturally prefers C's left behind shell. Hence, even if $\mathrm{D}$ places itself in the optimal position (i.e., immediately behind $\mathrm{C}$ ), this will not remove any incentives for $\mathrm{C}$ to continue helping as part of the original coalition. A separate problem, however, arises in terms of polyadic stability if a third party $\mathrm{D}$ arrives (see below).

\section{Smaller Coalition Member Must Not "Switch Teams" and Become Enemy}

Another way otherwise necessary, effective, and dyadically stable coalitions might be destabilized polyadically is if the smaller coalition member (C) turns on its partner (B), becoming an enemy (Figure 7). This dangerous flip is possible if a third party (D) arrives: for then $\mathrm{C}$ has the option of "switching teams" and teaming up with $\mathrm{D}$ in a new coalition, one where

\section{Coalition stable polyadically: third party is 'free rider' only}

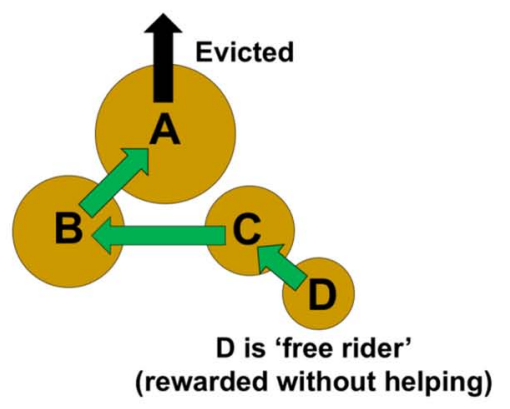

Coalition not stable polyadically:
undermined by third party 'cheater'

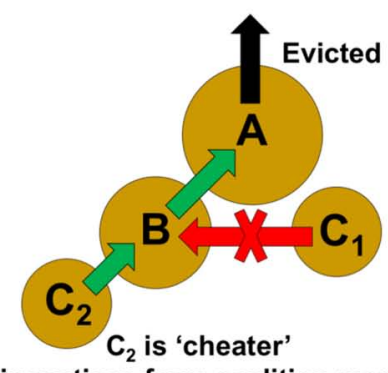

(steals incentives from coalition member $\mathrm{C}_{1}$ )

\section{Coalition not stable polyadically: former partner becomes enemy}

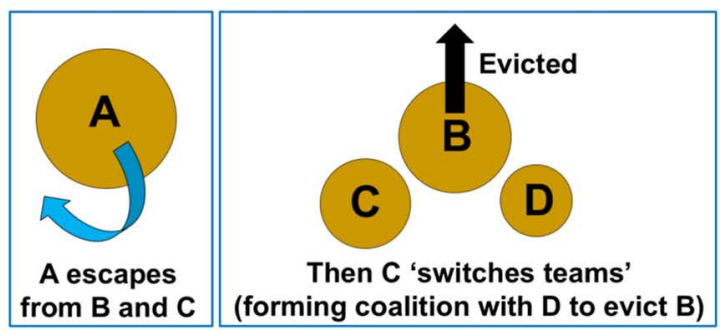

FIGURE 7 | For a coalition to form and be successful, it must be stable polyadically. In this case, a third-party "free rider" D will not undermine the coalition. D can benefit, despite not helping at all, since after the eviction succeeds, B and C will both move into their preferred shells, and then D can move into C's left behind shell. In contrast a coalition will not be stable polyadically if a third-party "cheater" $\left(\mathrm{C}_{2}\right)$ steals incentives from one of the coalition members $\left(\mathrm{C}_{1}\right)$ by placing itself in a superior position to move into B's left behind shell. Furthermore, a coalition will not be stable polyadically if a former coalition partner (C) "switches teams," turning on B to become an enemy, by forming a new coalition with $D$ to evict $B$. This scenario may arise if the original target (A) escapes, with only the triad (of $B, C$, and D) remaining.

its former coalition partner (B) now becomes the target of eviction. As more individuals from stair $\mathrm{D}$ arrive (e.g., $\mathrm{D}_{1}, \mathrm{D}_{2}$, $\mathrm{D}_{3}$, etc.) the likelihood increases that such a coalition switch will 
occur, undermining the original coalition arrangement. Polyadic instability from such upended coalitions will most likely be catalyzed if the original target (A) manages to escape, since then only the triad (of B, C, and D) is left. Yet whether C and D will then unite to form a coalition against $\mathrm{B}$ depends recursively on all the criteria outlined above, requiring that this new coalition be necessary, effective, stable dyadically, and stable polyadically.

\section{DISCUSSION}

\section{Insights From Conceptual Model}

The relevance of architecture for coalitions has rarely been considered, despite architecture permeating the lives of many animals (von Frisch, 1974; Hansell, 2005; Gould and Gould, 2007; Arndt and Tautz, 2013; Perna and Theraulaz, 2017; PinterWollman et al., 2017; Laidre, 2021a), and potentially having profound impacts on social dynamics and cooperation among non-kin. After laying an empirical foundation, based on the natural coalitions within the housing market of social hermit crabs, the main purpose of this paper was to then build a theoretical framework, which could predict when coalitions would form and be successful in an architectural context. The conceptual model predicts several key criteria that must hold if coalitions are to form and be successful: coalitions must be necessary, effective, stable dyadically, and stable polyadically. An overarching prediction of the model is that coalitions will only succeed when the distribution of architecture and power-among the coalition members and the evictee-yields an optimal route up the staircase for both members of the coalition to advance in the housing market. Interestingly, the model highlights a novel architectural solution for the evolution of cooperation among non-kin, by resolving the problem that often undermines coalitions_-"splitting the spoils"-based on variation in architectural preferences. This simple model of the architecture of coalitions could easily be modified and extended to other architectural contexts, possibly offering insights in other systems, where the constraints imposed by architecture may likewise align unrelated individuals' interests and ultimately fuel non-kin cooperation.

\section{Are Non-kin Coalitions Involving Architecture Unique to Certain Species?}

The coalitions described herein among hermit crabs have been observed and reported only in the highly social terrestrial genus Coenobita, not in other hermit crab species that are aquatic (e.g., Pagurus spp., Arnott and Elwood, 2007). Indeed, despite over 15 years of observations of these other, less social hermit crabs, neither the author, his students, or his collaborators have ever observed coalitions in any of these less social species (Laidre, 2007, 2009, 2011; Laidre and Elwood, 2008; Laidre and Greggor, 2015; Greggor and Laidre, 2016; Valdes and Laidre, 2018; Doherty and Laidre, 2020). Less social marine hermit crabs readily acquire new shells from sources other than conspecifics (Laidre, 2011; Valdes and Laidre, 2018), which likely nullifies any need for coalitions or non-kin cooperation among conspecifics.
Interestingly, less social marine hermit crabs do exhibit interspecific cooperative mutualisms (Bergstrom et al., 2003), in which other species provide valuable services in return for living on or inside a hermit crab's shell (e.g., anemones attached to a hermit crab shell protect the crab from octopus predation: Ross, 1971). Yet as for coalitions and intra-specific non-kin cooperation, these appear unique to the highly social terrestrial hermit crabs. In addition to coalitions, studies of highly social terrestrial hermit crabs have revealed that they differ in many other ways compared to less social marine hermit crabs (Laidre, 2014). Social hermit crabs exhibit the following traits in their fission-fusion (Couzin and Laidre, 2009) social groupings: a much stronger social attraction to conspecifics, both living (Laidre, 2010, 2013a,b; Steele and Laidre, 2019) and dead (Valdes and Laidre, 2019); an evolutionary loss of threat displays (Doherty and Laidre, 2020); specialized social cognition (Laidre, 2018b), including a nuanced understanding of fine-grained social formations (Bates and Laidre, 2018) and a capacity for problem-solving (Krieger et al., 2020); coordinated behaviors used in the social exchange of shells, which are passed down across generations (Laidre, 2019a); as well as an altered sexual morphology, which reduces the danger of shell theft during copulation (Laidre, 2019b). The greater sociality of these Coenobita spp. hermit crabs, compared to the less social marine hermit crabs, is linked to their extreme dependence on conspecifics for architecturally remodeled shells, which can only be acquired after conspecifics are evicted or die, and without which individuals cannot survive (Laidre, 2012b).

Further comparative studies can help resolve the phylogenetic limits of coalitions (Bracken-Grissom et al., 2013), potentially revealing additional hermit crab species that might form coalitions when ecological imperatives arise. Even more broadly, beyond hermit crabs, countless other social invertebrates are premier "animal architects" (Gould and Gould, 2007), which may therefore offer additional opportunities (Elgar, 2015) for exploring how and why architecture influences cooperation. Indeed, many species, from invertebrates to vertebrates, inhabit a wide range of burrows of variable size and shape, with individuals frequently evicting fellow conspecifics from their burrows [reviewed in Laidre (2018a)]. Paralleling the collaborative evictions in shell "housing markets" there could be scope for similar collaborative evictions in closely clustered burrows, where certain burrows may be more optimal for specific individuals, depending on their current state (e.g., size, reproductive status, or the presence of additional kin or non-kin that live with them). Furthermore, like the architecturally remodeled shells of social hermit crabs, many other forms of architecture are costly to excavate or to construct (Hansell, 2005), so there may be incentives for other animals to likewise find ways of circumventing such architectural costs by working together to evict current owners in a collaborative effort. Finally, given strong evidence that architecture has influenced cooperation among close kin (e.g., the fortresses of eusocial insects: Queller and Strassmann, 1998; Perna and Theraulaz, 2017; Varoudis et al., 2018), deeper study of architecture's potential impact on nonkin cooperation could be constructive, including further studies of non-kin cooperative nesting among invertebrates (Haney and Fewell, 2018) as well among vertebrates (Riehl, 2013). 


\section{Next Steps: Empirical Tests of Model's key Predictions}

The present contribution has generated a number of testable predictions, but these predictions remain solely in the theoretical realm and have yet to be explicitly and rigorously tested empirically. Such empirical tests represent the obvious next step (Table 1), and can be accomplished both by quantifying elements of natural coalitions in the wild and, even more powerfully, by conducting experimental tests, which can span field conditions as well as controlled laboratory conditions. Moving forward, social hermit crabs, which served as empirical inspiration, can offer a model empirical system for testing many of the theoretical framework's key predictions, thereby helping unearth how and why architecture and housing markets impact coalitions. Social hermit crabs, in particular, lend themselves well to critical experimental tests, since virtually all the variables of theorized importance (the size of individuals; the size of shells they occupy; the relative strength of each individual; the dyadic and polyadic combinations of individuals; and the presence or absence of additional third parties) can be precisely controlled and manipulated.

\section{Naturalistic Tests Based on Systematic Field Measurements}

Years of naturalistic field observations on coalitions among social hermit crabs have been made, but still many basic empirical questions remain, including the frequency with which these coalitions form across "fission-fusion" social groupings (Couzin and Laidre, 2009), which span beach and forest (Steele and Laidre, 2019). An important first empirical step will be collecting systematic field measurements during transects of the frequency, the relative success rate, and the exact composition of natural, spontaneously forming coalitions in the wild. Previously, my students, collaborators, and I have not interrupted ongoing coalitions. However, future studies can take two approaches, one naturalistic and one more invasive, each generating complementary data, which are relevant to testing key predictions of the theoretical framework. First, from a naturalistic approach, coalitions can be followed from their point of initial formation up until their natural end point, which involves either successful eviction or unsuccessful dissolution (i.e., the coalition members separate). At this natural end point, all individuals involved - the two coalition members, the eviction target, and any additional third parties-can be collected, and their shell sizes and bodies can be measured, thereby testing if their relative sizes align as predicted. Second, utilizing a more invasive approach, coalitions can be interrupted in their early stages, while they are still in progress but before their fate has been determined, with all individuals once again being collected. Then these individuals can be tested with a field portable "eviction machine" we recently engineered (Laidre and van Citters, unpublished), which can quantify the biomechanical costs underlying eviction, including both pulling force and resistance force. We can therefore measure the maximum pulling force of the two coalition members (independently and when combined) as well as the maximum resistance force of the eviction target. Altogether, these biomechanical measures, as well as shell size and body measures, can offer a first test of predictions about which distributions of power and architecture yield necessary, effective, and stable coalitions.

\section{Experimental Tests With Socially Engineered Groups}

Building on such naturalistic and semi-invasive studies, another step will be conducting experiments with socially engineered groups. Unlike many other coalition-forming animals (e.g., large mammals and primates: Harcourt and de Waal, 1992), which can be challenging to relocate or introduce into new groups, social invertebrates offer exquisite ease in terms of translocating individuals between groups and thereby forming new and artificial group compositions. This line of experimentation with socially engineered groups can be readily accomplished with social hermit crabs. In particular, individuals collected directly from the wild can be assembled into dyads and triads, including those that are predicted to be successful versus not, thereby directly testing how well theoretical predictions match reality in terms of coalition formation and success. For example, which coalitions are necessary and effective can be tested by creating combinations (such as only A and B; only A and C; or A, B, and C), with just the last assembly predicted to lead to A's eviction. Similarly, which coalitions are dyadically stable vs. unstable can also be tested, with $\mathrm{B}$ and $\mathrm{C}$ predicted to succeed at evicting $\mathrm{A}$, but with $B_{1}$ and $B_{2}$ predicted to destabilize, given that the members

TABLE 1 | Key open questions about coalitions in social hermit crabs.

- How frequently do coalitions form across variable social, spatial, and temporal dimensions, including different fission-fusion social groupings, different ecological settings spanning beach to forest, and different seasons?

- What is the success rate of coalitions and, if successful, then how long does eviction take?

- What are the relative shell sizes and body sizes of coalition members and their target?

- How powerful are coalition members (independently and together) in their pulling force compared to the resistance strength of their target?

- Which combinations of socially engineered groups are more likely to form successful coalitions?

- In what circumstances does the arrival of third-party cheaters and free riders undermine coalitions?

- Do coalition members to seek privacy during attempted evictions?

- Do eviction targets attempt to attract additional conspecifics to create confusion that destabilizes coalitions?

- How and why does architecture-from the fine-scale architecture within the interior of individual shells up to the large-scale architecture of an entire shell housing market-impact coalition formation and frequency?

To critically test the proposed theoretical framework, future field observations and experiments must answer the above questions. 
of the latter pair will prefer and hence compete over the target A's shell. In addition to testing variable social compositions, it will also be possible to explore how coalition formation changes with greater or lesser disparities between individuals, for example by altering what shell sizes specific individuals in the triad initially occupy, and even by impairing specific individuals' strength (e.g., weakening individuals via anesthesia: Osorno et al., 1998). A rich suite of experimental tests using socially engineered groups thus awaits.

\section{Experimental Tests With Third Parties}

One key prediction of the conceptual model is that for a coalition to be successful, its dyadic stability (which arises from the alignment of the two coalition members' interests) must not be undermined by polyadic instability (which arises through the arrival of third-party "cheaters" and "free riders"). This prediction - that third parties may imperil a coalition's stabilitycan be experimentally tested. For example, in the experiments mentioned above with socially engineered groups, a separate chamber door could be used to introduce third parties into the main group's arena, systematically varying the number and size of these third parties, as well as the time at which they are introduced. Likewise in the wild, it is possible to simulate the arrival of third parties via previously utilized experimental techniques, such as tethering live crabs (e.g., Laidre, 2010; Steele and Laidre, 2019); using dynamically moving models of dead conspecifics (e.g., Doherty and Laidre, 2020; see also Laidre and Vehrencamp, 2008); using empty shells that are either jostled (e.g., Laidre, 2013a) or dragged to simulate conspecific movement; or employing arrays of shells as stand-ins for social chains of conspecifics (e.g., Bates and Laidre, 2018). All these methods can test whether subtle changes in the surrounding polyadic social context undermine coalitions. Interestingly, given the potential hazard posed by third parties, it may be in the interests of both coalition members to seek privacy (Strassmann and Queller, 2014) during attempted evictions, not unlike how private locations are sought to evade shell theft during copulation (Laidre, 2019b). Also, from the perspective of the eviction target, the mere possibility that a coalition might be undermined by polyadic social complexity may incentivize the target to attract as many additional conspecifics as possible, in a desperate attempt to destabilize the coalition and create enough confusion for the target itself to escape. Prominent sounds that are produced by social hermit crabs while defending against eviction (Laidre and Symes, 2021) might function in such social eavesdropping, and this acoustic hypothesis can be tested in future playback experiments.

\section{Experimental Tests of Architecture: From Shell Interior up to Whole Housing Markets}

In addition to experiments with variable groups and third parties, the very nature of the underlying architecture can provide a source of powerful experimentation. Experimental alteration of architecture can be accomplished from the fine-scale (e.g., the inner architecture within an individual shell) up to the largescale (e.g., the overall size distribution of an entire shell housing market). Social hermit crabs architecturally remodel the interiors of shells, which is beneficial in terms of lightening the load they must carry on land (Herreid and Full, 1986; Trinh and Laidre, 2016). However, this architectural remodeling has a hidden cost: by eroding out much of the shell's interior, it means there is less for owners to grip upon when resisting eviction (Laidre, 2021c). Thus, in linking architecture to coalitions, one interesting hypothesis is that altering the available grip inside shells could impact the ability of owners to resist eviction, regardless of their baseline strength; and if owners are then more versus less hard to evict, it should in turn change whether coalitions are still necessary or effective. Recently, we have micro-CT scanned natural shells with substantial variation in inner shell grip and have also 3D printed shells with novel architectural variation (Krieger et al., 2020). Future experiments can test how such variation in fine-scale inner architecture impacts many aspects of coalition formation and the frequency with which they occur. Similarly, at the largest architectural scale of the entire shell housing market, the potential exists to alter the overall size distribution of this market, either by introducing or removing set sizes of shells. In theory, such altered size distributions of architecture could dramatically change localized competition levels, profoundly affecting available options for individuals seeking to move up in the housing market. Such architectural changes could also add social pressure on individuals at the top of the housing market, by making it more likely for "revolutionary" coalitions to be incited among those at the bottom or middle of the housing market. Long-term studies that experimentally change the size distribution of housing markets in wild populations thus have the tantalizing potential to test whether these changes also causally influence the frequency of coalitions and which specific coalitions form.

\section{Further Theoretical Work}

Finally, alongside these several strands of empirical work, further theoretical work on the intersection of architecture and coalitions could yield broader insights. The main focus herein was developing a relatively simple theoretical framework, which could serve as an initial conceptual model for making testable predictions and driving empirical inquiry. Yet future theoretical work on this topic could build on this foundation by developing more sophisticated formulations-agent-based computer simulations, analytical mathematical models, and game-theoretical models (Maynard Smith, 1982; Sigmund, 1993, 2010)-all of which can explore ramifications of altered ecological and social variables, including in the overall housing market. Coalitions inherently play out in a broader "housing market" as well as "social market" context (Noë et al., 2001; Roth, 2015), in which individuals have many choices for potential coalition partners, as well as for potential targets to evict. Thus, while the predicted criteria for necessary, effective, and stable coalitions appear concrete and straightforward, their computational complexity may be non-trivial due to the broader matrix of potential strategies playing out across an entire market. Coalitions deemed necessary, effective, and stable might nevertheless be ruled out due to alternative decisions by other individuals within the market: for instance, a seemingly necessary, effective, and stable coalition (between small C and 
medium B to evict large A) might be subverted if smaller individuals $\mathrm{D}$ and $\mathrm{E}$ team up to evict C. Future theoretical work should account for this complex matrix of strategies by winnowing down all potential coalitions to only those that remain viable in reference to power dynamics and architectural size distributions across the market as a whole. Such theoretical work could also explore how variable levels of conflicting versus aligned interests-in terms of the degree of overlap in architectural preference between two coalition members-shapes the outcome of coalitions, as well as which individuals form coalitions and the overall frequency of coalition formation. Ultimately stronger bridges can be built between theoretical and empirical work on this topic, with empirical data not only testing theory, but inspiring new theory (e.g., computational algorithms of "coalition formation" that integrate information on power and architecture to compute which coalitions function best).

\section{Summary and Future Prospects}

The present theoretical framework has sought to address a long-standing question in behavioral ecology and evolutionary biology by proposing a novel solution for the evolution of cooperation among non-kin: architectural constraints. Unlike prior explanations for non-kin cooperation, where "splitting the spoils" can undermine the cooperative relationship, this novel architectural solution predicts that the evolutionary interests of non-kin can coincide, particularly on an architectural staircase with discrete reusable resources, like shells. Coalitions among non-kin can therefore arise even as genetically unrelated individuals all selfishly pursue their own evolutionary interests, competing fiercely over scarce architectural resources. Future work in this area can profitably wed theory with experiment in an interdisciplinary approach spanning biology, engineering, and mathematics to better understand the coalitions that form in nature. The path from original observation to incipient hypotheses to simple conceptual models to experimental tests to full-blown theory is long and winding. Yet ultimately, continued research down this fascinating intellectual path can

\section{REFERENCES}

Abrams, P. (1978). Shell selection and utilization in a terrestrial hermit crab, Coenobita compressus (H. Milne Edwards). Oecologia 34, 239-253. doi: 10.1007/ BF00345169

Akçay, E. (2018). Collapse and rescue of cooperation in evolving dynamic networks. Nat. Commun. 9:2692. doi: 10.1038/s41467-018-05130-7

Akçay, E. (2020). Deconstructing evolutionary game theory: coevolution of social behaviors with their evolutionary setting. Am. Nat. 195, 315-330. doi: 10.1086/ 706811

Arndt, I., and Tautz, J. (2013). Animal Architecture. New York, NY: Abrams.

Arnott, G., and Elwood, R. W. (2007). Fighting for shells: how private information about resource value changes hermit crab pre-fight displays and escalated fight behaviour. Proc. R. Soc. B 274, 3011-3017. doi: 10.1098/rspb.2007. 1196

Arnott, G., and Elwood, R. W. (2008). Information gathering and decision making about resource value in animal contests. Anim. Behav. 76, 529-542. doi: 10. 1016/j.anbehav.2008.04.019

Axelrod, R. (1984). The Evolution of Cooperation. New York, NY: Basic Books. help build the architectural foundation of a better understanding of cooperative behavior.

\section{DATA AVAILABILITY STATEMENT}

The original contributions presented in the study are included in the article/supplementary material, further inquiries can be directed to the corresponding author/s.

\section{AUTHOR CONTRIBUTIONS}

ML conceived and designed the model, made the original empirical observations that inspired the model, and wrote the manuscript.

\section{FUNDING}

The conceptual model was produced without any explicit funding, other than support from the author's home institution of Dartmouth College.

\section{ACKNOWLEDGMENTS}

I thank the editors (Floria Mora-Kepfer Uy, Leticia Aviles, and Miriam Richards) for inviting this contribution to the special issue ("Social Invertebrates as Models for Non-Kin Cooperation"). Bella Li kindly created the illustration of a natural coalition based on my original photo. She also drew my attention to a book, from which the quote at the head of this manuscript derives. I am grateful to Feng Fu for years of valuable discussion about cooperation and coalitions, and to John Gilbert and two referees for constructive comments. My decade-long research program on social hermit crabs has been supported by NSF, the Miller Institute, the Neukom Institute, National Geographic, and Dartmouth College.

Bates, K. M., and Laidre, M. E. (2018). When to socialize: perception of timesensitive social structures among social hermit crabs. Anim. Behav. 138, 19-27.

Bergstrom, C. T., Bronstein, J. L., Bshary, R., Connor, R. C., Daly, M., Frank, S. A., et al. (2003). "Interspecific mutualisms: puzzles and predictions," in Genetic and Cultural Evolution of Cooperation, ed. P. Hammerstein (Cambridge: MIT Press), 241-256.

Bonner, J. T. (2006). Why Size Matters: From Bacteria To Blue Whales. Princeton, NJ: Princeton University Press.

Bourke, A. F. G. (2011). Principles of Social Evolution. New York, NY: Oxford University Press.

Bracken-Grissom, H. D., Cannon, M. E., Cabezas, P., Feldmann, R. M., Schweitzer, C. E., Ahyong, S. T., et al. (2013). A comprehensive and integrative reconstruction of evolutionary history for Anomura (Crustacea: Decapoda). BMC Evol. Biol. 13:128. doi: 10.1186/1471-2148-13-128

Clutton-Brock, T. (2009). Cooperation between non-kin in animal societies. Nature 462, 51-57. doi: 10.1038/nature08366

Couzin, I. D., and Laidre, M. E. (2009). Fission-fusion populations. Curr. Biol. 19, R633-R635.

de Saint-Exupéry, A. (1945/2017). The Little Prince. London: Egmont. 
Doherty, C. T. M., and Laidre, M. E. (2020). Evolutionary loss of threat display in more social species: phylogenetic comparisons, natural interactions in the wild, and experiments with models. Behaviour 157, 1025-1058. doi: 10.1163/ 1568539x-bja10038

Elgar, M. A. (2015). Integrating insights across diverse taxa: challenges for understanding social evolution. Front. Ecol. Evol. 3:124. doi: 10.3389/fevo.2015. 00124

Gould, J. L., and Gould, C. G. (2007). Animal Architects: Building and the Evolution of Intelligence. New York, NY: Basic Books.

Greggor, A. L., and Laidre, M. E. (2016). Food fights: aggregations of marine hermit crabs (Pagurus samuelis) compete equally for food-and shell-related carrion. Bull. Mar. Sci. 92, 293-303. doi: 10.5343/bms.2015.1054

Hamilton, W. D. (1964a). The genetical evolution of social behaviour. I. J. Theor. Biol. 7, 1-16.

Hamilton, W. D. (1964b). The genetical evolution of social behaviour. II. J. Theor. Biol. 7, 17-52. doi: 10.1016/0022-5193(64)90039-6

Hammerstein, P. (ed.) (2003). Genetic and Cultural Evolution of Cooperation. Cambridge: MIT Press.

Haney, B. R., and Fewell, J. H. (2018). Ecological drivers and reproductive consequences of non-kin cooperation by ant queens. Oecologia 187, 643-655. doi: 10.1007/s00442-018-4148-9

Hansell, M. (2005). Animal Architecture. New York, NY: Oxford University Press.

Harcourt, A. H., and de Waal, F. B. M. (eds) (1992). Coalitions and Alliances in Humans and Other Animals. New York, NY: Oxford University Press.

Herreid, C. F., and Full, R. J. (1986). Energetics of hermit crabs during locomotion: the cost of carrying a shell. J. Exp. Biol. 120, 297-308. doi: 10.1242/jeb.120.1.297

Krieger, J., Hörnig, M. K., and Laidre, M. E. (2020). Shells as 'extended architecture': to escape isolation, social hermit crabs choose shells with the right external architecture. Anim. Cogn. 23, 1177-1187. doi: 10.1007/s10071-02001419-7

Laidre, M. E. (2007). Vulnerability and reliable signaling in conflicts between hermit crabs. Behav. Ecol. 18, 736-741. doi: 10.1093/beheco/arm040

Laidre, M. E. (2009). How often do animals lie about their intentions? An experimental test. Am. Nat. 173, 337-346. doi: 10.1086/596530

Laidre, M. E. (2010). How rugged individualists enable one another to find food and shelter: field experiments with tropical hermit crabs. Proc. R. Soc. B 277, 1361-1369. doi: 10.1098/rspb.2009.1580

Laidre, M. E. (2011). Ecological relations between hermit crabs and their shellsupplying gastropods: constrained consumers. J. Exp. Mar. Biol. Ecol. 397, 65-70. doi: 10.1016/j.jembe.2010.10.024

Laidre, M. E. (2012a). Homes for hermits: temporal, spatial and structural dynamics as transportable homes are incorporated into a population. J. Zool. 288, 33-40. doi: 10.1111/j.1469-7998.2012.00921.x

Laidre, M. E. (2012b). Niche construction drives social dependence in hermit crabs. Curr. Biol. 22, R861-R863. doi: 10.1016/j.cub.2012.08.056

Laidre, M. E. (2013a). Eavesdropping foragers use level of collective commotion as public information to target high quality patches. Oikos 122, 1505-1511.

Laidre, M. E. (2013b). Foraging across ecosystems: diet diversity and social foraging spanning aquatic and terrestrial ecosystems by an invertebrate. Mar. Ecol. 34, 80-89. doi: 10.1111/j.1439-0485.2012.00527.x

Laidre, M. E. (2014). The social lives of hermits. Nat. Hist. 122, 24-29.

Laidre, M. E. (2018a). "Evolutionary ecology of burrow construction and social life," in Life Histories, eds G. A. Wellborn and M. Thiel (New York, NY: Oxford University Press), 279-301.

Laidre, M. E. (2018b). "Social cognition in the wild: from lab to field in hermit crabs," in Field and Laboratory Methods in Animal Cognition: A Comparative Guide, eds N. Bueno-Guerra and F. Amici (New York, NY: Cambridge University Press), 237-239.

Laidre, M. E. (2019a). Architectural modification of shells by terrestrial hermit crabs alters social dynamics in later generations. Ecology 100:e02767. doi: 10. $1002 /$ ecy. 2767

Laidre, M. E. (2019b). Private parts for private property: evolution of penis size with more valuable, easily stolen shells. R. Soc. Open Sci. 6:181760. doi: 10.1098/ rsos. 181760

Laidre, M. E. (2019c). Life, in a nutshell. Front. Ecol. Environ. 17:202. doi: 10.1002/ fee. 2041

Laidre, M. E. (2021a). Animal architecture. Curr. Biol. 31, R1458-R1464.
Laidre, M. E. (2021b). From behavior to architecture and back: the evolution of social ('so-shell') life in social hermit crabs. Int. Comp. Biol. 61, E490-E491.

Laidre, M. E. (2021c). Social conquest of land: sea-to-land changes in shell architecture and body morphology, with consequences for social evolution. Arthrop. Struct. Dev. 63:101064. doi: 10.1016/j.asd.2021.101064

Laidre, M. E., and Elwood, R. W. (2008). Motivation matters: cheliped extension displays in the hermit crab, Pagurus bernhardus, are honest signals of hunger. Anim. Behav. 75, 2041-2047. doi: 10.1016/j.anbehav.2007.11.011

Laidre, M. E., and Greggor, A. L. (2015). Swarms of swift scavengers: ecological role of marine intertidal hermit crabs in California. Mar. Biol. 162, 969-977. doi: 10.1007/s00227-015-2639-3

Laidre, M. E., and Johnstone, R. A. (2013). Animal signals. Curr. Biol. 23, R829R833.

Laidre, M. E., and Symes, L. B. (2021). "Sounds from the home: bioacoustics and animal architecture," in Proceedings of the Conference Presentation at the Animal Behavior Society 2021 Meeting.

Laidre, M. E., and Trinh, R. (2014). Unlike terrestrial hermit crabs, marine hermit crabs do not prefer shells previously used by conspecifics. Crustaceana 87, 856-865. doi: 10.1163/15685403-00003320

Laidre, M. E., and Vehrencamp, S. L. (2008). Is bird song a reliable signal of aggressive intent? Behav. Ecol. Sociobiol. 62, 1207-1211. doi: 10.1007/s00265007-0539-3

Laidre, M. E., and Vermeij, G. J. (2012). A biodiverse housing market in hermit crabs: proposal for a new biodiversity index. Res. J. Costa Rican Distance Educ. Univ. 4, 175-179. doi: 10.22458/urj.v4i2.5

Laidre, M. E., Patten, E., and Pruitt, L. (2012). Costs of a more spacious home after remodelling by hermit crabs. J. R. Soc. Interface 9, 3574-3577. doi: 10.1098/rsif. 2012.0501

Maynard Smith, J. (1982). Evolution and the Theory of Games. New York, NY: Cambridge University Press.

Mesterton-Gibbons, M., and Dugatkin, L. A. (1992). Cooperation among unrelated individuals: evolutionary factors. Q. Rev. Biol. 67, 267-281. doi: 10.1086/417658

Mesterton-Gibbons, M., Gavrilets, S., Gravner, J., and Akçay, E. (2011). Models of coalition or alliance formation. J. Theor. Biol. 274, 187-204. doi: 10.1016/j.jtbi. 2010.12.031

Noë, R. (1990). A veto game played by baboons: a challenge to the use of the Prisoner's Dilemma as a paradigm for reciprocity and cooperation. Anim. Behav. 39, 78-90. doi: 10.1016/s0003-3472(05)80728-6

Noë, R. (1994). A model of coalition formation among male baboons with fighting ability as the crucial parameter. Anim. Behav. 47, 211-213. doi: 10.1006/anbe. 1994.1024

Noë, R., von Hooff, J. A. R. A. M., and Hammerstein, P. (eds) (2001). Economics in Nature: Social Dilemmas, Mate Choice and Biological Markets. New York, NY: Cambridge University Press.

Nowak, M., and Highfield, R. (2012). SuperCooperators: Altruism, Evolution, and Why We Need Each Other to Succeed. New York, NY: Free Press.

Nowak, M. A. (2006). Five rules for the evolution of cooperation. Science 314, 1560-1563. doi: 10.1126/science. 1133755

Osorno, J. L., Contreras-Garduño, J., and Macías-Garcia, C. (2005). Long-term costs of using heavy shells in terrestrial hermit crabs (Coenobita compressus) and the limits of shell preference: an experimental study. J. Zool. 266, 377-383.

Osorno, J.-L., Fernández-Casillas, L., and Rodríguez-Juárez, C. (1998). Are hermit crabs looking for light and large shells? Evidence from natural and field induced shell exchanges. J. Exp. Mar. Biol. Ecol. 222, 163-173.

Perna, A., and Theraulaz, G. (2017). When social behaviour is moulded in clay: on growth and form of social insect nests. J. Exp. Biol. 220, 83-91. doi: 10.1242/jeb. 143347

Pinter-Wollman, N., Fiore, S., and Theraulaz, G. (2017). The impact of architecture on collective behaviour. Nat. Ecol. Evol. 1:0111. doi: 10.1038/s41559-017-0111

Queller, D. C., and Strassmann, J. E. (1998). Kin selection and social insects. Bioscience 48, 165-175.

Riehl, C. (2013). Evolutionary routes to non-kin cooperative breeding in birds. Proc. R. Soc. B 280:20132245. doi: 10.1098/rspb.2013.2245

Roberts, L., and Laidre, M. E. (2019). Get off my back: vibrational assessment of homeowner strength. Biol. Lett. 15:20180819. doi: 10.1098/rsbl.2018.0819

Ross, D. M. (1971). Protection of hermit crabs (Dardanus spp.) from octopus by commensal sea anemones (Calliactis spp.). Nature 230, 401-402. doi: 10.1038/ $230401 \mathrm{a} 0$ 
Roth, A. E. (2015). Who Gets What - and Why: the New Economics of Matchmaking and Market Design. New York, NY: Mariner Books.

Rubenstein, D. R., and Abbot, P. (2017). Comparative Social Evolution. New York, NY: Cambridge University Press.

Scales, H. (2015). Spirals in Time: The Secret Life and Curious Afterlife of Seashells. New York, NY: Bloomsbury Sigma.

Shettleworth, S. J. (2010). Cognition, Evolution, and Behavior. New York, NY: Oxford University Press.

Sigmund, K. (1993). Games of Life: Explorations in Ecology, Evolution, and Behaviour. New York, NY: Oxford University Press.

Sigmund, K. (2010). The Calculus of Selfishness. Princeton, NJ: Princeton University Press.

Sober, E., and Wilson, D. S. (1999). Unto Others: The Evolution and Psychology of Unselfish Behavior. Cambridge: Harvard University Press.

Steele, E. P., and Laidre, M. E. (2019). Leaf me alone: visual constraints on the ecology of social group formation. Behav. Ecol. Sociobiol. 73:53.

Strassmann, J. E., and Queller, D. C. (2014). Privatization and property in biology. Anim. Behav. 92, 305-311.

Trinh, R. C., and Laidre, M. E. (2016). Niche constructed shells are built for locomotion: enhanced mobility, in the sea and on land, by terrestrial hermit crabs. Int. Comp. Biol. 56:E225.

Trivers, R. L. (1971). The evolution of reciprocal altruism. Q. Rev. Biol. 46, 35-57.

Valdes, L., and Laidre, M. E. (2018). Resolving spatio-temporal uncertainty in rare resource acquisition: smell the shell. Evol. Ecol. 32, 247-263. doi: 10.1007/ s10682-018-9937-4

Valdes, L., and Laidre, M. E. (2019). Scent of death: evolution from sea to land of an extreme collective attraction to conspecific death. Ecol. Evol. 9, 2171-2179. doi: $10.1002 /$ ece 3.4912
Varoudis, T., Swenson, A. G., Kirkton, S. D., and Waters, J. S. (2018). Exploring nest structures of acorn dwelling ants with X-ray microtomography and surface-based three-dimensional visibility graph analysis. Phil. Trans. R. Soc. B 373:20170237. doi: 10.1098/rstb.2017.0237

Vermeij, G. J. (1993). A Natural History of Shells. Princeton, NJ: Princeton University Press.

Vermeij, G. J. (2010). The Evolutionary World: How Adaptation Explains Everything From Seashells to Civilization. New York, NY: Thomas Dunne.

von Frisch, K. (1974). Animal Architecture. New York, NY: Harcourt.

Conflict of Interest: The author declares that the research was conducted in the absence of any commercial or financial relationships that could be construed as a potential conflict of interest.

Publisher's Note: All claims expressed in this article are solely those of the authors and do not necessarily represent those of their affiliated organizations, or those of the publisher, the editors and the reviewers. Any product that may be evaluated in this article, or claim that may be made by its manufacturer, is not guaranteed or endorsed by the publisher.

Copyright (c) 2021 Laidre. This is an open-access article distributed under the terms of the Creative Commons Attribution License (CC BY). The use, distribution or reproduction in other forums is permitted, provided the original author(s) and the copyright owner(s) are credited and that the original publication in this journal is cited, in accordance with accepted academic practice. No use, distribution or reproduction is permitted which does not comply with these terms. 